\title{
Who is Interested in Personality? The Interest in Personality Scale and its Correlates
}

\author{
Abstract \\ This research introduces the Interest in Personality Scale (IPS), a self-report measure assessing \\ individual differences in interest in, and attentiveness to, others' personalities. Seven studies \\ were meta-analyzed to examine the correlates of the IPS, and participants $(N=1,004)$ were \\ drawn from student and online population. The IPS demonstrated good internal reliability, and it \\ correlated significantly with a number of traits and demographic characteristics. People who \\ scored higher on the IPS were more likely to be women and to be younger; described themselves \\ as more agreeable, conscientious, extraverted, open to experience, dominant, empathic, \\ masculine, feminine, agentic, communal, and narcissistic; and reported more positive relations \\ with others. Emotion recognition and humanitarianism correlated positively with IPS marginally. \\ Neuroticism, a bipolar femininity-masculinity scale, personal distress, and Machiavellianism \\ were unrelated to the IPS.
}

Keywords: Interest in personality, personality scale, interests, meta-analysis 


\section{Who is Interested in Personality? The Interest in Personality Scale and its Correlates}

Imagine that Luke and Leia meet for the first time at a party. Leia might inquire about Luke's upbringing, or listen closely to his telling of how he reacted to past events, in order to get a better picture of him as a person. All of their exchanges at the party ultimately help Leia form an understanding of Luke's personality. Luke, on the other hand, may be less interested in knowing Leia or anyone else at the party; he does not care much about trying to understand other people and their personalities. Leia might think personality is an important and fascinating phenomenon, while Luke might not even believe people have predictable behavioral signatures. Luke and Leia differ in what we are calling "interest in personality," a construct for which we developed a self-rating measuring instrument.

We could not locate a comparable or similar scale in the literature. One might interpret this lack of research on interest in personality as being indicative of its triviality or irrelevance. Yet personality-related judgments are highly common, and highly impactful; how an individual perceives a target person influences his or her behavior toward that person (Harris \& Garris, 2008). Individuals readily attribute behaviors in the moment to personality rather than to environmental or external influences, a tendency so common it is said to be fundamental (Gilbert \& Malone, 1995). People do not make such dispositional attributions randomly, however; research has shown that people are more accurate than chance at judging the personality traits of both acquainted people and strangers (for a review, see Connelly \& Ones, 2010), and can do so using only minimal amounts of information (Carney, Colvin, \& Hall, 2007; Naumann, Vazire, Rentfrow, \& Gosling, 2009).

Although the level of skill seen in personality judgment when examined at the group level is non-trivial, as indexed above, there also exists substantial variability in such skill 
between individuals (Letzring, 2008; Vogt \& Colvin, 2003). While some individuals are "good judges," and are able to form highly accurate impressions of target persons, others are consistently inaccurate. The ability to reason about personality-relevant information has been proposed as a central component of the personal intelligence construct (Mayer, Panter, \& Caruso, 2012). Mayer, Wilson, and Hazelwood (2010) proposed that individuals who are more accurate at judging others' personality use their knowledge to make better choices in interpersonal actions and, ultimately, to manage their social and professional lives in a more adept way. Though many correlates of interpersonal accuracy have been identified (Hall, Schmid Mast, \& West, 2016), interest in personality may also play an important, yet unexamined, role that could extend beyond the judgment of personality to include judgments of other characteristics of people such as their emotions or personal attributes, to the extent that being interested in personality implies being interested in all individual aspects of another person.

In this article, we present the Interest in Personality Scale (IPS) to measure people's interest in others' personalities and examine the correlates of such an interest. The IPS consists of self-ratings of the importance of others' personalities for oneself, the extent to which one thinks about others' personalities, and accuracy in perceiving others' personalities. Example items are "I think a lot about how people differ in their personalities," "Another person's personality means a lot in terms of how I treat him/her," and "When I meet someone new, I immediately have an impression of their personality" (see Table 1 for all the items). The central aim of this research is to uncover who is interested in personality.

The IPS was first developed and used in the process of validating a performance-based measure of accuracy in judging personality from reading first-person text excerpts (called Assessing Personality from Text, or APT; Hall, Goh, Schmid Mast, \& Hagedorn, 2015). In that 
research, the IPS correlated positively with accuracy in judging personality on the APT. Across three studies, the mean correlation was .18 and highly significant. This provided evidence that people who were interested in personality were also more accurate judges of personality traits presented in the written medium. Hall et al. (2015) limited their reporting of the IPS to its correlations with the APT; however, in three of the APT's validation studies, the IPS was used in conjunction with a number of other variables. These we report for the first time in the present article, along with correlates from four new studies. Furthermore, we extend previous research by examining the IPS' connection to interpersonal judgment accuracy in another domain: emotion recognition.

For the present article, we combined results from seven studies in our laboratory that included the IPS, and we used meta-analysis to summarize the results (Goh, Hall, \& Rosenthal, 2016). We selected a priori all of the variables in relation to the IPS that represented a range of demographics and personality traits, and which were included in at least two of the seven studies. The next section describes our expectations regarding the correlates of the IPS.

\section{Overview of Variables}

Gender. Gender was examined in all seven studies. Gender differences have been documented for many variables relating to social perception and social interaction, including nonverbal behavior (Hall, 1984), accuracy of judging emotion and personality (Thompson \& Voyer, 2014; Vogt \& Colvin, 2003), attachment to peers (Gorrese \& Ruggieri, 2012), and leadership styles (Eagly, Johannesen-Schmidt, \& van Engen, 2003). In all of these domains women have emerged as more socially skilled or people-oriented relative to their male counterparts. It follows that there may be a similar gender difference for interest in personality. Compared to men, women are more interested in careers that involve working with other people 
(Su, Rounds, \& Armstrong, 2009). Indeed, perceived communal goal affordances influence women's interest in science careers; that is, women express less interest than men in going into the sciences because they perceive the field as less likely to offer communal goals such as working and helping other people (Diekman, Brown, Johnston, \& Clark, 2010). This individual difference in interest in working with people may be tied to interest in personality, such that demonstrating an interest in personality is reflective of an interest in people more generally, and the motivation to understand what makes each person unique.

Age. Age was examined in all seven studies. One might predict that increasing maturity brings more appreciation and refined understanding of personality differences between people and interest in them. On the other hand, social circles tend to decrease as one ages and this decrease might be associated with less interest in others' personalities.

Self-reported personality. In five studies we measured all Big Five traits (Agreeableness, Conscientiousness, Extraversion, Neuroticism, and Openness to Experience), as well as Dominance. Agreeableness was measured in two additional studies, making it the only trait measured in all seven studies. Of the Big Five traits, Agreeableness, Extraversion, and Dominance are the most intrinsically interpersonal in nature in that they are defined in terms of how one relates to other people. Therefore, they can be expected to positively correlate with the IPS. No relationship is assumed with Conscientiousness, Neuroticism, and Openness to Experience because these traits relate more to intrapersonal experience and how one engages with the intellectual or non-social world.

Four studies included the Personal Attributes Questionnaire (PAQ). The PAQ's Masculinity and Femininity scales both represent adaptive personality traits that are considered desirable for both male and female genders, but more so for one gender than the other. All of the 
items of the Femininity scale are very interpersonal and people-oriented in nature (e.g., warm, understanding, helpful), and therefore should correlate positively with the IPS. The items of the Masculinity scale prioritize self-concerns over concern for others, yet several of them do imply attention to others if only to set oneself apart (superior, competitive, independent); the relationship between masculinity and the IPS may be weak or there may be no relationship. In contrast, the bipolar Femininity-Masculinity scale of the PAQ contains items that are considered desirable for only one gender or the other. Because the items on this scale are very gender stereotypic, high scores on them may not be particularly adaptive for either gender. As examples, two items at the Feminine pole are very strong need for security and feelings easily hurt, and two items at the Masculine pole are indifferent to others' approval and very aggressive. Additionally, two studies measured Agency and Communion, which are theoretically similar to Masculinity and Femininity, respectively. Similar to Masculinity, Agency measures self-concerns and selfpromotion. Similar to Femininity, Communion measures concern and respect for others.

The Interpersonal Reactivity Index (IRI) was given in four of the studies. The subscales of the IRI (Fantasy, Empathic Concern, Perspective Taking, and Personal Distress) reflect several ways of relating emotionally and cognitively to the experience of real or imagined others. Of these four traits, Empathic Concern and Perspective Taking are the ones most related to interpersonal settings and might show stronger relations with the IPS.

Two studies measured variables related to quality of social relations. Positive social relations were measured using the Positive Relations with Others scale and Humanitarianism/Egalitarianism scale. Narcissism and Machiavellianism were included to measure negative social relations. It is expected that IPS would correlate positively with positive 
relation measures, but there would be negative or no relationship with the negative social relation measures.

Emotion recognition ability. Three studies included tests of accuracy in judging target persons' emotions based on audiovisual cues. Tests such as these have been shown to be related to a wide range of personal characteristics, including several of the Big Five traits, the empathy construct, and Femininity (Hall, Andrzejewski, \& Yopchick, 2009). The IPS has previously been shown to correlate positively with accuracy in judging personality (Hall et al., 2015); in the current research we examine whether the IPS may also predict judgment accuracy in the emotion recognition domain using three different audiovisual tests.

Below, each study's method is described, followed by the integration using metaanalysis.

\section{Method}

\section{Interest in Personality Scale}

Table 1 shows the items of the IPS. Items were answered on a 7-point scale $(1=$ Strongly Disagree; 7 = Strongly Agree). The nine items (items 2, 5, and 7 being reversed) were averaged to form a total score for interest in personality. Higher scores reflect more self-reported interest in personality.

\section{Study 1}

Participants were 118 Amazon Mechanical Turk (MTurk) workers (51\% female; $M_{\text {age }}=$ 31.95; age range $=19-71)$ who were paid $\$ 1.50$. Participation was limited to native English speakers from the United States and at least 18 years of age. In addition to the IPS, gender was measured and was coded 0 for male and 1 for female, so that point-biserial correlations with the IPS would be positive if women scored higher and negative if men scored higher. Age was self- 
reported. The Big Five traits were measured with the Ten Item Personality Inventory (TIPI; Gosling, Rentfrow, \& Swann, 2003). Two new items to measure Dominance were added, using the same format as the TIPI: "Dominant, controlling" and "A follower more than a leader, nonassertive" (reversed). Higher scores reflected more Dominance. The PAQ (Spence \& Helmreich, 1978) was included, which measured stereotypically masculine and feminine traits in three subscales: Masculinity, Femininity, and a bipolar Femininity-Masculinity scale (higher scores indicate more masculinity over femininity). Examples for each of the three subscales respectively are "very passive...very active," "very rough...very gentle" and "very submissive...very dominant." Finally, the IRI (Davis, 1983) contained four subscales (Fantasy, Empathic Concern, Perspective Taking, and Personal Distress). Examples for each of the four subscales respectively are "I really get involved with the feelings of the characters in a novel," "I would describe myself as a pretty soft-hearted person," "I believe that there are two sides to every question and try to look at them both," and "I tend to lose control during emergencies."

\section{Study 2}

Participants were 123 MTurk workers $\left(67 \%\right.$ female; $M_{\text {age }}=36.12$; age range $\left.=20-84\right)$ who were paid \$1.50. Participation was again limited to native English speakers from the United States and workers had to be at least 18 years old. Study 2 was a direct replication of Study 1 and had the same materials.

\section{Study 3}

Participants were 404 MTurk workers (64\% female; $M_{\text {age }}=36.21$; age range $=18-74$ ) who were paid \$1.50. Exclusion criteria were the same as Studies 1 and 2. These participants reported their gender and age and completed the IPS, TIPI, and Dominance scale.

\section{Study 4}


Fifty-two undergraduate students $\left(60 \%\right.$ female; $M_{\text {age }}=19.77$; age range $\left.=18-30\right)$ participated in this study for course credit. Participants completed the study on computers in a laboratory, with maximally two participants being tested at the same time. All participants were either native English speakers or were fluent in English. The following measures described earlier were administered: The IPS, TIPI, IRI, and PAQ. In addition, participants completed three tests measuring emotion recognition ability; the short version of the Geneva Emotion Recognition Test (GERT-S; Schlegel \& Scherer, in press), and the Face and Voice tests of the Diagnostic Analysis of Nonverbal Accuracy (DANVA, Nowicki \& Duke, 1994). The GERT-S consists of 42 brief video clips in which actors express 14 different emotions. After each clip participants are asked to choose which of the 14 emotions they think was being expressed. Responses are scored as correct (1) or incorrect (0) and used to calculate a mean emotion recognition score. The DANVA-faces consists of 24 photographs of facial expressions of students that express happiness, sadness, anger, or fear. The DANVA-voices consists of 24 audio recordings in which actors say the sentence "I am going out of the room now but I'll be back later” in a happy, fearful, sad, or angry tone. After each picture or recording, participants are asked to choose which of the four emotions had been expressed. Responses are scored as correct (1) or incorrect (0) and form a total score for each of the two subtests. The correlations for each of the three tests with the IPS were averaged to form one single effect size.

\section{Study 5}

Forty-one MTurk workers (native English speakers and living in the United States) participated in this study for a payment of $\$ 2$. Twenty-four participants (59\%) were female, and age ranged from 18 to 60 with a mean of 36.37. As in Study 4, participants completed the IPS, TIPI, IRI, PAQ, GERT-S, DANVA-faces, and DANVA-voices. 


\section{Study 6}

Eighty-three undergraduate students $\left(60 \%\right.$ female; $M_{\text {age }}=19.27$; age range $\left.=17-30\right)$ participated for course credit. Participants completed the study on computers in a laboratory, with maximally two participants being tested at the same time. Participants completed the DANVA-faces. Agreeableness was measured using the NEO-PI-R Agreeableness Subscale (Costa \& McCrae, 1992), and example items include "I would rather cooperate with others than compete with them" and "I try to be courteous to everyone I meet." Ryff's Positive Relations with Others Subscale (Ryff, 1989) was included, and example items include "I enjoy personal and mutual conversations with family members or friends" and "My friends and I sympathize with each other's problems.” Humanitarianism/Egalitarianism scale (Katz \& Hass, 1988) included items such as "One should be kind to all people" and "A person should be concerned about the well-being of others." The Agency-Communion scale (Trapnell \& Paulhus, 2012) asked participants to rate the importance of agentic (e.g., "wealth" and "status") and communal (e.g., "trust" and "harmony") values. Narcissism was measured with the NPI-16 scale (Ames, Rose, \& Anderson, 2006), and items include "I really like to be the center of attention" and I like having authority over people." Finally, Machiavellianism was measured using the MACHIV (Christie \& Geis, 1970) and examples include "Anyone who completely trusts anyone else is asking for trouble" and "It is wise to flatter important people."

\section{Study 7}

Participants were 183 MTurk workers $\left(63 \%\right.$ female; $M_{\text {age }}=36.75$; age range $=19$ - 77) who were paid \$1.50. Exclusion criteria were the same as Studies 1 and 2. With the exclusion of DANVA-faces, all variables in Study 6 were included in Study 7.

\section{Statistical Analysis}


The correlations between the IPS and each individual variable were used in the mini meta-analyses ("mini" because each is based on only a few studies). The magnitude of effect sizes as conventionally defined is small $(r=.10)$, medium $(r=.30)$, or large $(r=.50)$ (Cohen, 1988). Due to similarity in research design and the use of identical instruments, the fixed-effects approach was taken in which the mean effect size (i.e., mean correlation) was weighted so that larger studies received more weight, under the assumption that there is one underlying true effect size that the studies are all estimating for a given comparison. The mean effect size was then tested against zero. All correlations were Fisher's $z$ transformed for analyses and converted back to Pearson correlations for presentation. The Comprehensive Meta-Analysis Software program was used for analyses (Borenstein, Hedges, Higgins, \& Rothstein, 2005). All analyses were based on two-tailed tests.

\section{Results}

\section{Descriptive Statistics}

Descriptive statistics of the IPS in the seven studies are shown in Table 2. In general, participants had a fairly high level of interest in personality, with means of approximately 5 on a 7-point scale in all seven studies. Participants also exhibited a wide range of scores (range $=2.33$ to 7.00). The scale's nine items showed good internal reliability across the seven studies with a median Cronbach's alpha of .73 (range $=.63$ to .82$){ }^{1}$

\section{Gender and Age}

Gender $($ male $=0$; female $=1$ ) positively correlated with the IPS such that women scored higher than men (Table 3). Combining all seven studies, men scored 4.99 on average (range $=$ $2.67-6.89$ ) and women scored 5.22 on average (range $=2.33-7.00$ ). While the difference as expressed in the point-biserial correlation was small (Cohen, 1988), it was nonetheless 
significant. Because there was a significant gender difference on the IPS, we performed the meta-analyses for all other variables twice: once using partial correlations calculated by controlling for gender, and once using zero-order correlations that did not control for gender. There were no appreciable differences in results when gender was controlled, so all analyses presented below were based on zero-order correlations that did not control for gender.

As for age, a negative relationship was observed (Table 3). Younger participants indicated more interest in personality than their older counterparts. Given that five of the seven studies used online community samples with a wide age range (e.g., age ranged from 18 to 71 in Study 1), the effect was not restricted by the narrow age range of typical college samples.

\section{Personality Correlates}

Excluding Neuroticism, all other facets of the Big Five traits (Agreeableness, Extraversion, Conscientiousness, and Openness to Experience) were positively correlated with the IPS. More interest in personality was associated with more Agreeableness, more Conscientiousness, more Extraversion, and more Openness to Experience. Additionally, more Dominance was also positively correlated with interest in personality (see Table 3).

Both Masculinity and Femininity from the PAQ were correlated positively with the IPS, and the same was true for the Agency and Communion scales. However, the PAQ's bipolar Femininity-Masculinity did not correlate significantly. As stated earlier, the effects held after controlling for gender (see Table 4).

With the exception of Personal Distress, all subscales of the IRI (Fantasy, Empathic Concern, and Perspective Taking) were positively correlated with the IPS (see Table 5).

Participants who reported having more positive relations with other people scored higher on the IPS, as well as people embracing more Humanitarian/Egalitarian values. Surprisingly, 
participants higher in Narcissism also scored higher on the IPS. Machiavellianism was not related to the IPS (see Table 6).

\section{Interpersonal Accuracy Tests}

The relationship between accuracy on the GERT and the IPS showed a small effect that was marginally significant, $M r=.18, Z=1.71, p=.087$. Accuracy on the DANVA faces test had a similar degree of association with the IPS, $M r=.14, Z=1.84, p=.066$. There was no relationship between the DANVA voices test and the IPS, $M r=.07, Z=.63, p=.528$.

\section{Discussion}

As social animals, human beings have a fundamental need to connect with others and to understand them, both in the moment and in terms of their stable characteristics (i.e., their personality). This research introduced a new scale that measures individual differences in people's interest in personality. Across seven studies with over 1,000 participants, the Interest in Personality Scale (IPS) demonstrated good internal reliability and significant relationships with personality traits, demographic characteristics, and marginally significant relationships with emotion recognition ability.

People who reported being more interested in personality were more likely to be female, consistent with traditions of research reviewed earlier (e.g., Thompson \& Voyer, 2014; Vogt \& Colvin, 2003). A negative correlation between age and scores on the IPS was also found. This finding aligns with previous research on older adults' decreased desire to expand their social circles, as compared to younger adults (Antonucci, Akiyama, \& Takahashi, 2004). New acquaintanceship often necessitates that both parties demonstrate a certain level of interest to foster a meaningful friendship; if one or both parties have little desire to expand their social 
circle, interest in personality would be lower. However, the mediating role of social circle in explaining the relationship between age and the IPS needs to be examined in the future.

Higher scores on the IPS were positively correlated with a number of personality traits that suggested a positive attitude toward other people and interest in them: Agreeableness, Extraversion, Femininity and Communion, Empathic Concern, Perspective Taking, Fantasy (i.e., immersive experience or identification with fictional characters or plotline), and Humanitarianism/Egalitarianism. People more interested in personality also reported having more positive relations with other people. These results suggest that being interested in personality is indicative of a socially skilled, interpersonally adaptive, and well-adjusted personality (e.g., Block, 2008; Cohen, Panter, Turan, Morse, \& Kim, 2014). That the IPS was not significantly related to Neuroticism, Personal Distress (e.g., avoidant anxiety and discomfort when witnessing others' suffering), Machiavellianism, or the extremely gender-stereotypic Femininity-Masculinity scale of the PAQ bolsters this interpretation, as high scores on these traits connote negative interpersonal experience or less psychological integration (e.g., Block, 2008).

Two other traits that had significant positive associations with the IPS Conscientiousness and Openness to Experience — are not immediately apparent as having particularly prosocial or interpersonal connotations. On the other hand, they too are traits of people with good adjustment (Block, 2008), and are predictive of moral character (Cohen et al., 2014) and positive citizenship behavior (Cohen, Panter, Turan, Morse, \& Kim, 2013).

Dominance, Masculinity, and Agency also had significant positive associations with the IPS. Though these traits lack the prosocial connotations of the first group of correlated variables, they too can be socially functional at moderate levels (Helgeson, 1994). 
Accuracy on tests of identifying emotions from nonverbal cues was somewhat related to the IPS. The GERT and DANVA faces tests both yielded marginally significant effects that were of similar magnitude as found in Hall et al. (2015) between accuracy of judging personality from text excerpts (i.e., APT test) and the IPS $(r=.18)$. Therefore, in magnitude there is some evidence to suggest that interest in personality bears a relation to accurate interpersonal perception across domains as well as relation to performance-based measures and not just selfreports. Because accurate interpersonal perception has been shown to be correlated with a wide range of socially and personally adaptive traits (e.g., Hall et al., 2009), this result too gives some credence to the interpretation that interest in personality is an adaptive trait.

The only trait not to fit within this general conceptualization of socially healthy adaptation is Narcissism, which had a significant positive association with interest in personality. Narcissists are not generally considered to have a prosocial orientation toward others (e.g., Park \& Colvin, 2014). However, research also suggests that individuals high in narcissism tend to be likeable and popular at first impression and early acquaintance (Leckelt, Küfner, Nestler, \& Back, 2015). The interpersonal attractiveness of narcissists at first sight may be due to their interest in the personalities of others, even if such interest is only the means to an exploitative or self-serving end. Specifically, the exploitative component of narcissism requires a degree of interest and attentiveness in other people in order for manipulation and exploitation to succeed. Indeed, there is evidence showing that the exploitative subscale of Narcissism is positively associated with accuracy in judging negative emotions in others, presumably because the vulnerable nature of negative emotions in others allows for more opportunities to be exploited (Konrath, Corneille, Bushman, \& Luminet, 2014). Still, narcissism is also frequently associated with biases in both self- and other- perception (Park \& Colvin, 2014), suggesting the need for 
future research. Regardless, this positive association with Narcissism suggests that IPS may not always reflect good adjustment, and showing interest in others' personality may afford certain individuals with opportunities to exploit and manipulate others. It is also the case that on the narcissism scale used in the present research, only a few items focused on the self; most actually alluded to comparisons to others, or to the attention received from others. Indeed, a hallmark of narcissism is the need for others' admiration. Seeking praise from others and manipulating them to attain it may necessarily entail being interested in them as individuals. In that sense, being interested in personality, though antithetical to narcissistic individuals' worldviews and enduring characteristics, may have short-term utility and serve as a means to an end.

Although the current studies generally provided support for the notion that interest in personality is an adaptive social trait, it should be noted that most of the effect sizes obtained would be classified as "small" according to conventional standards within the field (Cohen, 1988). Nonetheless, these effect sizes indicating the strength of the relationship between the IPS and other self-reported personality traits ( $r$ s hovering around .20 to .30 ) are similar to those obtained in a host of other scale development and construct validity studies of highly frequently utilized scales such as the Interpersonal Reactivity Index (Davis, 1983), the Narcissistic Personality Inventory (Watson, Grisham, Trotter, \& Biderman, 1984), and the Need for Cognition Scale (Osberg, 1987), among others. Furthermore, effect sizes of this magnitude are typical and expected within the field of personality research more generally (Funder, 1999; Kenrick \& Funder, 1988).

Another limitation lies in the scale construction. Undoubtedly, the IPS would benefit from inclusion of more items that can potentially examine different underlying facets of a 
person's interest in one's own and others' personality. A crucial first step in the future would be to expand the IPS and examine correlates of potentially different facets of interest in personality. The current research investigated a number of correlates among individuals who showed interest and attentiveness to other people's personality. These correlates suggest that interest in personality may be an adaptive interpersonal trait, but one that is not necessarily prosocial in its uses. Although more research is needed to explore the behavioral outcomes of interest in personality such as accurate interpersonal judgments from social interactions, the present research suggests this personality trait may have important implications for cross-domain interpersonal sensitivity. 


\section{References}

Ames, D. R., Rose, P., \& Anderson, C. P. (2006). The NPI-16 as a short measure of narcissism. Journal of Research in Personality, 40, 440-450.

Antonucci, T. C., Akiyama, H., \& Takahashi, K. (2004). Attachment and close relationships across the life span. Attachment and Human Development, 6, 353-370.

Block, J. (2008). The Q-sort in character appraisal: Encoding subjective impressions of persons quantitatively. Washington, DC: American Psychological Association.

Borenstein, M., Hedges, L., Higgins, J., \& Rothstein, H. (2005). Comprehensive meta-analysis, 2nd edition. Englewood, NJ: Biostat.

Carney, D. R., Colvin, C. R., \& Hall, J. A. (2007). A thin slice perspective on the accuracy of first impressions. Journal of Research in Personality, 41, 1054-1072.

Christie, R., \& Geis, F. L. (1970). Studies in Machiavellianism. New York: Academic Press.

Cohen, J. (1988). Statistical power analysis for the behavioral sciences (2nd edition). Hillsdale, NJ: Lawrence Erlbaum Associates.

Cohen, T. R., Panter, A. T., Turan, N., Morse, L., \& Kim, Y. (2013). Agreement and similarity in self-other perceptions of moral character. Journal of Research in Personality, 47, 816830.

Cohen, T. R., Panter, A. T., Turan, N., Morse, L., \& Kim, Y. (2014). Moral character in the workplace. Journal of Personality and Social Psychology, 107, 943-963.

Connelly, B. S., \& Ones, D. S. (2010). An other perspective on personality: Meta-analytic integration of observers' accuracy and predictive validity. Psychological Bulletin, 136, 1092-1122. 
Costa, P. T., Jr., \& McCrae, R. R. (1992). Revised NEO Personality Inventory (NEO-PR-R) and NEO Five Factor Inventory (NEO-FFI) professional manual. Odessa, FL: Psychological Assessment Resources.

Davis, M. H. (1983). Measuring individual differences in empathy: Evidence for a multidimensional approach. Journal of Personality and Social Psychology, 44, 113-126.

Diekman, A. B., Brown, E. R., Johnston, A. M., \& Clark, E. K. (2010). Seeking congruity between goals and roles: A new look at why women opt out of science, technology, engineering, and mathematics careers. Psychological Science, 21, 1051-1057.

Eagly, A. H., Johannesen-Schmidt, M. C., \& Van Engen, M. L. (2003). Transformational, transactional, and laissez-faire leadership styles: A meta-analysis comparing women and men. Psychological Bulletin, 129, 569-591.

Funder, D. C. (Ed.). (1999). Personality judgment: A realistic approach to person perception. San Diego, CA: Academic Press.

Gilbert, D. T., \& Malone, P. S. (1995). The correspondence bias. Psychological Bulletin, 117, 21-38.

Goh, J. X., Hall, J. A., \& Rosenthal, R. (2016). Mini meta-analysis of your own studies: Some arguments on why and a primer on how. Manuscript submitted for publication.

Gorrese, A., \& Ruggieri, R. (2012). Peer attachment: A meta-analytic review of gender and age differences and associations with parent attachment. Journal of Youth and Adolescence, 41, 650-672.

Gosling, S. D., Rentfrow, P. J., \& Swann, W. B., Jr. (2003). A very brief measure of the Big-Five personality domains. Journal of Research in Personality, 37, 504-528. 
Hall, J. A. (1984). Nonverbal sex differences: Accuracy of communication and expressive style. Johns Hopkins University Press.

Hall, J. A., Andrzejewski, S. A., \& Yopchick, J. E. (2009). Psychosocial correlates of interpersonal sensitivity: A meta-analysis. Journal of Nonverbal Behavior, 33, 149-180.

Hall, J. A., Goh, J. X., Schmid Mast, M., \& Hagedorn, C. (2015). Individual differences in accurately judging personality from text. Journal of Personality.

Hall, J. A., Schmid Mast, M., \& West, T. V. (Eds.) (2016). The social psychology of perceiving others accurately. Cambridge, UK: Cambridge University Press.

Harris, M. J., \& Garris, C. P. (2008). You never get a second chance to make a first impression: Behavioral consequences of first impressions. In N. Ambady \& J. J. Skowronski (Eds.), First impressions (pp. 147-168). New York, NY: Guilford Press.

Helgeson, V. S. (1994). Relation of agency and communion to well-being: Evidence and potential explanations. Psychological Bulletin, 116, 412-428.

Katz, I., \& Hass, R. G. (1988). Racial ambivalence and American value conflict: Correlational and priming studies of dual cognitive structures. Journal of Personality and Social Psychology, 55, 893-905.

Kenrick, D. T., \& Funder, D. C. (1988). Profiting from controversy: Lessons from the personsituation debate. American Psychologist, 43, 23-34.

Konrath, S., Corneille, O., Bushman, B. J., \& Luminet, O. (2014). The relationship between narcissistic exploitativeness, dispositional empathy, and emotion recognition abilities. Journal of Nonverbal Behavior, 38, 129-143. 
Leckelt, M., Küfner, A. C., Nestler, S., \& Back, M. D. (2015). Behavioral processes underlying the decline of narcissists“ popularity over time. Journal of Personality and Social Psychology, 109, 856-871.

Letzring, T. D. (2008). The good judge of personality: Characteristics, behaviors, and observer accuracy. Journal of Research in Personality, 42, 914-932.

Mayer, J. D., Panter, A. T., \& Caruso, D. R. (2012). Does personal intelligence exist? Evidence from a new ability-based measure. Journal of Personality Assessment, 94, 124-140.

Mayer, J. D., Wilson, R., \& Hazelwood, M. (2010). Personal intelligence expressed: A multiple case study of business leaders. Imagination, Cognition, and Personality, 30, 201-224.

Muthén, L.K., \& Muthén, B.O. (2011). Mplus User’s Guide (6th ed.). Los Angeles, CA: Muthén \& Muthén.

Naumann, L. P., Vazire, S., Rentfrow, P. J., \& Gosling, S. D. (2009). Personality judgments based on physical appearance. Personality and Social Psychology Bulletin, 35, 16611671.

Nowicki, S., \& Duke, M. P. (1994). Individual differences in the nonverbal communication of affect: The Diagnostic Analysis of Nonverbal Accuracy Scale. Journal of Nonverbal Behavior, 18, 9-35.

Osberg, T. M. (1987). The convergent and discriminant validity of the need for cognition scale. Journal of Personality Assessment, 51, 441-450.

Park, S. W., \& Colvin, C. R. (2014). Narcissism and discrepancy between self and friends' perceptions of personality. Journal of Personality, 82, 278-286.

Ryff, C. D. (1989). Happiness is everything, or is it? Explorations on the meaning of psychological well-being. Journal of Personality and Social Psychology, 57, 1069-1081. 
Schlegel, K., \& Scherer, K. R. (in press). Introducing a short version of the Geneva Emotion Recognition Test (GERT-S): Psychometric properties and construct validation. Behavior Research Methods.

Spence, J. T., \& Helmreich, R. L. (1978). Masculinity and femininity: Their psychological dimensions, correlates and antecedents. Austin: University of Texas Press.

Su, R., Rounds, J., \& Armstrong, P. I. (2009). Men and things, women and people: A metaanalysis of sex differences in interests. Psychological Bulletin, 135, 859-884

Thompson, A. E., \& Voyer, D. (2014). Sex differences in the ability to recognise non-verbal displays of emotion: A meta-analysis. Cognition and Emotion, 28, 1164-1195.

Trapnell, P. D., \& Paulhus, D. L. (2012). Agentic and communal values: Their scope and measurement. Journal of Personality Assessment, 94, 39-52.

Vogt, D. S., \& Colvin, C. R. (2003). Interpersonal orientation and the accuracy of personality judgments. Journal of Personality, 71, 267-295.

Watson, P. J., Grisham, S. O., Trotter, M. V., \& Biderman, M. D. (1984). Narcissism and empathy: Validity evidence for the Narcissistic Personality Inventory. Journal of Personality Assessment, 48, 301-305. 


\section{Footnote}

${ }^{1}$ In order to assess the dimensional structure of the Interest in Personality Scale (IPS), we ran an exploratory factor analysis (EFA) of the nine items specifying the extraction of one to three factors. This analysis was conducted in MPlus (Muthén \& Muthén, 2010) using the combined data from all seven studies. The confirmatory fit index (CFI), root mean square error of approximation (RMSEA), and standardized root mean square residual (SRMR) were inspected to assess model fit. While the one-factor model did not fit the data well $\left(\chi^{2}=405.547, d f=27, p<\right.$ $.001, \mathrm{CFI}=.767, \mathrm{RMSEA}=.118, \mathrm{SRMR}=.066)$, the two-factor model showed good fit $\left(\chi^{2}=\right.$ $82.950, d f=19, p<.001, \mathrm{CFI}=.961, \mathrm{RMSEA}=.058, \mathrm{SRMR}=.027)$. The Geomin rotated loading matrix showed that Items 1 and 2 (reversed) were the only items that highly and significantly loaded on the second factor (loadings were .830 and .675 , respectively). The loadings for all other items on this factor were below .30. The two factors were correlated at $r=$ $.431(p<.05)$. Items 1 and 2 both refer to the time a person spends thinking about personality, a nuance that is not explicitly part of the other items. The three-factor EFA fit the data slightly better than the two-factor solution $\left(\chi^{2}=42.268, d f=12, p<.001, \mathrm{CFI}=.981\right.$, RMSEA $=.050$, SRMR $=.019)$, but the loading matrix was not readily interpretable due to many cross-loadings. However, results showed similar correlational patterns with external variables for both factors. Given these findings and considering that the second factor consisted of only two items and was significantly correlated with the first factor, we recommend the usage of the average score over all nine IPS items. All presented results used the average of all nine items. 
Table 1

Items on the Interest in Personality Scale (IPS)

1 I think a lot about how people differ in their personalities

2 I don't spend much time comparing people I know in terms of their personalities (R)

3 Another person's personality matters a lot in terms of how I treat him or her

4 When I meet someone new, I immediately have an impression of their personality

5 There's no such thing as 'personality types' (R)

6 I am generally right on target when I assess someone's personality

7 If you asked me to describe the personalities of my friends, I probably couldn't do a good job of it (R)

8 I like to describe people's personalities when I talk about them to friends or family

9 A person's personality is reflected in how they act and in what they say

Note. $\mathrm{R}=$ item reversed in scoring. All items were measured on a 1 (Strongly Disagree) to 7 (Strongly Agree) scale. 
Table 2

Descriptive Statistics for Interest in Personality Scale

\begin{tabular}{lcccc}
\hline Study & $N$ & $M(S D)$ & Range & Cronbach's alpha \\
\hline 1: Online & 118 & $5.08(.72)$ & $3.22-6.78$ & .67 \\
2: Online & 123 & $5.16(.79)$ & $3.11-7.00$ & .80 \\
3: Online & 404 & $5.23(.75)$ & $2.67-6.89$ & .73 \\
4: Lab & 52 & $5.43(.65)$ & $4.00-6.78$ & .63 \\
5: Online & 41 & $5.01(.85)$ & $3.56-7.00$ & .82 \\
6: Lab & 83 & $5.18(.70)$ & $3.22-6.67$ & .72 \\
7: Online & 183 & $4.86(.76)$ & $2.33-6.78$ & .74
\end{tabular}

Note. All items were measured on a 1 (Strongly Disagree) to 7 (Strongly Agree) scale. 
Table 3

Correlations of the Interest in Personality Scale with Gender, Age, Big Five Traits, and Dominance

\begin{tabular}{lllllllll}
\hline Study $^{\mathrm{a}}$ & Gender & Age & $\mathrm{A}$ & $\mathrm{C}$ & $\mathrm{E}$ & $\mathrm{N}$ & $\mathrm{O}$ & Dom. \\
\hline 1 & .03 & -.11 & $.24^{* *}$ & $.29^{* *}$ & $.22^{*}$ & -.06 & $.20^{*}$ & .08 \\
2 & $.28^{* *}$ & $-.19^{*}$ & .14 & $.18^{*}$ & $.20^{*}$ & .05 & $.23^{* *}$ & $.23^{* *}$ \\
3 & $.13^{* *}$ & $-.13^{* *}$ & $.10^{*}$ & .07 & $.14^{* *}$ & $.10^{*}$ & $.19^{* * *}$ & $.13^{* *}$ \\
4 & .21 & -.16 & .05 & .17 & .17 & .04 & $.32^{*}$ & $.30^{*}$ \\
5 & .25 & -.20 & $.40^{* *}$ & $.38^{*}$ & .24 & -.19 & $.50^{* * *}$ & .13 \\
6 & $.22^{*}$ & -.12 & -.05 & - & - & - & - & - \\
7 & $.12^{+}$ & -.10 & .00 & - & - & - & - & - \\
$M r$ & $.15^{* * *}$ & $-.13^{* * *}$ & $.10^{* *}$ & $.15^{* * *}$ & $.17^{* * *}$ & .05 & $.23^{* * *}$ & $.15^{* * *}$
\end{tabular}

Note. $\mathrm{A}=$ Agreeableness; $\mathrm{C}=$ Conscientiousness $\mathrm{E}=$ Extraversion; $\mathrm{N}=$ Neuroticism; $\mathrm{O}=$ Openness to Experience; Dom. $=$ Dominance; $M r=$ fixed-effects weighted mean correlation across studies. Gender was coded as male $=0$; female $=1$; positive correlations indicate that women scored higher on the Interest in Personality Scale than men. $P$-values for $M r$ are metaanalytic tests of the mean correlation against zero.

${ }^{a}$ Some sample sizes are slightly reduced due to occasional missing observations. ${ }^{+} p \leq .10 . * p \leq .05 . * * p \leq .01 . * * * p \leq .001$. 
Table 4

Correlations of the Interest in Personality Scale with Masculinity, Femininity, FemininityMasculinity, Agency, and Communion

\begin{tabular}{|c|c|c|c|c|c|}
\hline Study & Masculinity & Femininity & Fem.-Masc. & Agency & Communion \\
\hline 1 & $.15^{+}$ & $.33 * * *$ & $-.16^{+}$ & - & - \\
\hline 2 & $.29 * * *$ & $.25 * *$ & .03 & - & - \\
\hline 4 & .21 & $.32 *$ & .15 & - & - \\
\hline 5 & $.28^{+}$ & $.51 * * *$ & .06 & - & - \\
\hline 6 & - & - & - & $.36 * * *$ & $.33 * *$ \\
\hline 7 & - & - & - & $.19 * *$ & $.18 * *$ \\
\hline$M r$ & $.23 * * *$ & $.32 * * *$ & -.02 & $.24 * * *$ & $.23 * * *$ \\
\hline
\end{tabular}

Note. Fem.-Masc. = Femininity-Masculinity (bipolar scale); $M r=$ fixed-effects weighted mean correlation across studies. $P$-values for $M r$ are meta-analytic tests of the mean correlation against zero.

${ }^{+} p \leq .10 .{ }^{*} p \leq .05 .{ }^{* *} p \leq .01 .{ }^{* * *} p \leq .001$. 
Table 5

Correlations of the Interest in Personality Scale with Interpersonal Reactivity Index

\begin{tabular}{lcccc}
\hline Study & Fantasy & Perspective taking & Empathic concern & Personal distress \\
\hline 1 & $.24 * *$ & $.32^{* * *}$ & $.38^{* * *}$ & .10 \\
2 & $.24 * *$ & .02 & $.15^{+}$ & -.07 \\
4 & $.24^{+}$ & $.25^{+}$ & .20 & $-.26^{+}$ \\
5 & $.64 * * *$ & $.51^{* * *}$ & $.45^{* *}$ & $-.28^{+}$ \\
$M r$ & $.30^{* * *}$ & $.23 * * *$ & $.28 * * *$ & -.07 \\
\hline
\end{tabular}

Note. $M r=$ fixed-effects weighted mean correlation across studies. $P$-values for $M r$ are metaanalytic tests of the mean correlation against zero.

${ }^{+} p \leq .10 .{ }^{* *} p \leq .01 . * * * p \leq .001$. 
Table 6

Correlations of the Interest in Personality Scale with Positive Relations with Others, Humanitarianism/Egalitarianism, Narcissism, and Machiavellianism

\begin{tabular}{lcccc}
\hline Study & Positive Relations & Humanitarianism & Narcissism & Machiavellianism \\
\hline 6 & $.26^{*}$ & .17 & $.30^{* *}$ & .18 \\
7 & $.14^{+}$ & .09 & $.22^{* *}$ & -.12 \\
$M r$ & $.18^{* *}$ & $.12^{+}$ & $.25^{* * *}$ & -.03 \\
\hline
\end{tabular}

Note. $M r$ = fixed-effects weighted mean correlation across studies. $P$-values for $M r$ are metaanalytic tests of the mean correlation against zero.

${ }^{+} p \leq .10 .{ }^{*} p \leq .05 .{ }^{* *} p \leq .01 .{ }^{* * *} p \leq .001$. 